\title{
Measuring mechanical anisotropy on geogrid reinforced soil using a cubical triaxial apparatus
}

\author{
Pedro A. Covassi ${ }^{1}$ and Víctor A. Rinaldi ${ }^{1 *}$ \\ ${ }^{1}$ National University of Córdoba, Civil Engineering Department, 1611 Vélez Sársfield Ave., Argentina
}

\begin{abstract}
This work describes the main findings of an experimental program focused on the characterization of the mechanical anisotropy of a reinforced cohesive soil using a cubical triaxial apparatus. Several authors have studied the influence of geometry, type, number and arrangement of reinforcement layers on the mechanical behaviour of reinforced soils, mainly dedicated to evaluate the improvement of stiffness and strength. The influence of anisotropy and principal intermediate stress has not been addressed. Conventional triaxial cell (axisymmetric) and pull-out tests are the most common type of devices used in the present studies. The implementation of an experimental program using a cubical triaxial apparatus allows us to consider all the aspects mentioned before, mainly those related to an anisotropic characterization and the principal intermediate stress influence on stress-strain and strength behaviour. Results obtained in this work, show that reinforced soil is a cross-anisotropic material, and its stress-strain and strength behaviour is strongly influenced in sectors I (lode angle between $0^{\circ}$ and $60^{\circ}$ ) and II (lode angle between $60^{\circ}$ and $120^{\circ}$ ) of the octahedral plane. Thus, a complete characterization of geogrid reinforced soil can be made selecting an appropriate set of stress paths in the cubical apparatus.
\end{abstract}

\section{Introduction}

Soil reinforcement using geosynthetics is one of the most used techniques on these days in the engineering practice for improvement and stabilization of soils. However, the inclusion of reinforcing elements in the soil may affects the anisotropic behaviour of the soil mass, especially when the reinforcement has a preferential orientation such as is the case of for example geogrids, geotextiles and steel strips. In general, the main factors that influence the anisotropic behaviour of reinforced soil are [1]:

- Anisotropy increases with increasing the number of reinforcing layers.

- Anisotropy increases with increasing in the reinforcement stiffness.

- $\quad$ Stiffness and strength anisotropy of reinforced soil mass change with the reinforcement orientation with respect to the load direction.

Therefore, when analysing a reinforced soil structure, both, the inherent anisotropy of compacted soil and the influence of reinforcement on the anisotropic response of the reinforced soil mass must be considered. Likewise, the influence of the stress path on the stress-strain and strength behaviour must be taken in consideration. In this experimental study of anisotropy, two parameters are used to describe the shear stress path applied to the sample [2]:

1. The angle $\delta$, which is defined as the direction of the main principal stress relative to the direction of deposition of soil (generally is considered vertical).
2. The parameter $b=\left(\sigma_{2}-\sigma_{3}\right) /\left(\sigma_{I^{-}} \sigma_{3}\right)$, which represents the influence of the intermediate principal stress. Being $\sigma_{1}, \sigma_{2}$ and $\sigma_{3}$ the main, intermediate and minor principal stress components respectively.

These two parameters allow to evaluate the influence of the stress path direction relative to the direction of soil deposition and reinforcement orientation, in order to describe the anisotropy of reinforced soil in terms of stiffness and strength.

Finite element approaches for reinforced soils analysis can be classified into three main categories: nonhomogeneous, homogeneous anisotropic [1, 3-7] and anisotropic multiphase [8-12]. The last two approaches require the implementation of constitutive formulations for the composite material that are, in general, more complex than those used to describe the behaviour of their individual components. The results of experimental studies can provide the basis for the development of these formulations.

Among the various tests used to evaluate reinforced soils, unconfined compression and conventional triaxial (axisymmetric) compression tests are the most commonly found in the literature [13-18]. Research usually studied the influence of the type of reinforcement, shape and number of geosynthetic layers for the improvement in stiffness and strength of the composite material. Most of these investigations were performed on cohesionless soils, and to a lesser extent on cohesive soils (silts and clays). There is limited information related to the influence of principal stresses orientation and inherent

\footnotetext{
* Corresponding author: vrinaldi@unc.edu.ar
} 
and induced anisotropy on the mechanical behaviour of reinforced soils. The main studies performed for these purposes used plane strain devices [19-21].

This work summarizes the main results of an experimental program designed to characterize the anisotropic behaviour of compacted soil and the influence of reinforcement using a cubical triaxial apparatus [22]. Thus, various samples were prepared by compaction with and without reinforcement. All samples where then tested in the cubical triaxial apparatus for different stress paths which were selected for a unique octahedral plane. The results allow us to evaluate also the influence of the orientation of the reinforcement.

\section{Experimental program}

\subsection{Materials and specimen preparation}

The soil used in this work was obtained from the campus of the National University of Córdoba, Argentina. It is a low plastic aeolian clayey silt (Pampean Loess). The main physical properties of the selected soil are summarized in Table 1. The maximum dry unit weight of the soil obtained in the Proctor Standard compaction test was $16.25 \mathrm{kN} / \mathrm{m}^{3}$ and the optimum moisture content was $18.7 \%$.

Table 1. Main physical properties of the soil tested here.

\begin{tabular}{|c|c|c|c|c|c|}
\hline $\begin{array}{c}\text { LL } \\
{[\mathbf{\%}]}\end{array}$ & $\begin{array}{c}\text { PI } \\
{[\mathbf{\%}]}\end{array}$ & Gs & $\begin{array}{c}\text { Pass. \#40 } \\
\text { sieve } \\
{[\mathbf{4 2 5} \boldsymbol{\mu \mathbf { m } ]}}\end{array}$ & $\begin{array}{c}\text { Pass. \#200 } \\
\text { sieve } \\
{[\mathbf{7 4} \boldsymbol{\mu m}]}\end{array}$ & USCS \\
\hline 24.3 & 5.5 & 2.67 & 100 & 81.3 & ML \\
\hline
\end{tabular}

Note: LL: liquid limit; PI: plasticity index; Gs: specific gravity; USCS: Unified Soil Classification System.

The reinforcement selected was a bidirectional geogrid, made of high density polyethylene (HDPE) extruded polymer, with $2.0 \times 2.0 \mathrm{~mm}$ openings and $0.3 \mathrm{~mm}$ in thickness. Tensile strength was $3.5 \mathrm{kN} / \mathrm{m}$.

The soil was prepared as recommended by Sivakumar and Wheeler [23] before compaction. Unreinforced soil specimens were statically compacted in four layers of $2 \mathrm{~cm}$ in thickness each in an $80 \mathrm{~mm}$ side cubical mould following the procedure of Cui and Delage [24]. Reinforced soil specimens were also compacted statically following the same procedure but in eight layers of $1 \mathrm{~cm}$ in thickness each. A reinforcement sheet was placed between each soil layer. Thus, seven reinforcement sheets were located in each sample. This amount of reinforcement represents the $0.45 \%$ by weight with respect to the dry soil. All the specimens were compacted at $15 \mathrm{kN} / \mathrm{m}^{3}$ of dry unit weight which corresponds to the $92.5 \%$ of optimum.

\subsection{Testing Program}

The prepared specimens were immediately installed inside the cubical triaxial cell. Filter paper was placed on the six faces of specimen to facilitate saturation and drainage during consolidation and shear. After permeation with carbon dioxide under low pressure gradient, saturation was achieved using deionized water at an effective confining stress of $10 \mathrm{kPa}$, until the total volume of water passing through the specimen was at least equal to three times the initial volume of the specimen. After saturation, a $100 \mathrm{kPa}$ backpressure was applied gradually, keeping an effective confinement level of $10 \mathrm{kPa}$. A minimum Skempton's pore pressure parameter B value of 0.95 was adopted to consider the full saturation of the specimens. Each specimen was then consolidated under isotropic pressure during 24 hours and the volumetric deformation with time was registered. Drained triaxial shear stress path was applied at a load rate of $6 \mathrm{kPa} / \mathrm{hr}$. During shear, the lateral displacements on each face of the sample and the volumetric strains were measured.

Two isotropic compression (IC) tests were performed on reinforced and unreinforced specimens using a maximum isotropic confining pressure of $300 \mathrm{kPa}$, using load increments of $10 \mathrm{kPa}$. For each loading step, the displacements on each direction were measured until full stabilization before applying the next loading step.

Triaxial shear tests were performed at $80 \mathrm{kPa}$ constant effective mean stress and constant Lode angle $(\theta)$ stress paths on seven unreinforced and seven reinforced specimens. In all the triaxial shear tests, the direction of compaction was coincident with the $z$ axis of the device. All selected stress paths yield in the same octahedral plane while the Lode angle was varied from $0^{\circ}$ to $180^{\circ}$ every $30^{\circ}$ (i.e. $0^{\circ}, 30^{\circ}, 60^{\circ}, \ldots, 180^{\circ}$ ), by rotating the orientation of the principal stresses for each stress path applied. The experimental program is summarized in Table 2 .

\section{Experimental results}

\subsection{Isotropic compression tests}

Figure 1 shows the effective mean stress versus principal strain curves obtained from isotropic compression (IC) tests performed on unreinforced and reinforced soil specimens. It is observed in this figure, that both unreinforced and reinforced soil specimens have crossanisotropy response under IC, being the stiffness in the vertical direction $(z)$ larger than in the horizontal $x$ and $y$ directions. Also, notice that the behaviour in the horizontal plane $x-y$ is isotropic. The main difference between the two tests is observed in the $z$ direction for which the compressibility of the reinforced specimen is lightly higher than that of the unreinforced one. This effect is clearly due to the higher compressibility of the geogrid material with respect to that of the compacted soil. 
Table 2. Summary of the experimental program.

\begin{tabular}{|c|c|c|c|c|c|}
\hline Test & $\begin{array}{c}\text { Stress } \\
\text { path }\end{array}$ & $\begin{array}{c}\text { Specimen } \\
\text { type }\end{array}$ & $\begin{array}{c}\text { Sector in } \\
\text { octahedral } \\
\text { plane }\end{array}$ & $\begin{array}{c}\boldsymbol{\theta} \\
\text { [ }^{\circ}\end{array}$ & $\boldsymbol{b}$ \\
\hline IC-U & IC & Unreinforced & - & - & - \\
\hline IC-R & IC & Reinforced & - & - & - \\
\hline TC-0-U & TC & Unreinforced & I & 0 & 0.0 \\
\hline SS-30-U & SS & Unreinforced & I & 30 & 0.5 \\
\hline TE-60-U & TE & Unreinforced & I-II & 60 & 1.0 \\
\hline SS-90-U & SS & Unreinforced & II & 90 & 0.5 \\
\hline TC-120-U & TC & Unreinforced & II-III & 120 & 0.0 \\
\hline SS-150-U & SS & Unreinforced & III & 150 & 0.5 \\
\hline TE-180-U & TE & Unreinforced & III & 180 & 1.0 \\
\hline TC-0-R & TC & Reinforced & I & 0 & 0.0 \\
\hline SS-30-R & SS & Reinforced & I & 30 & 0.5 \\
\hline TE-60-R & TE & Reinforced & I-II & 60 & 1.0 \\
\hline SS-90-R & SS & Reinforced & II & 90 & 0.5 \\
\hline TC-120-R & TC & Reinforced & II-III & 120 & 0.0 \\
\hline SS-150-R & SS & Reinforced & III & 150 & 0.5 \\
\hline TE-180-R & TE & Reinforced & III & 180 & 1.0 \\
\hline
\end{tabular}

Note: IC: isotropic compression; TC: triaxial compression; SS: simple shear; TE: triaxial extension; U: unreinforced; R: reinforced.

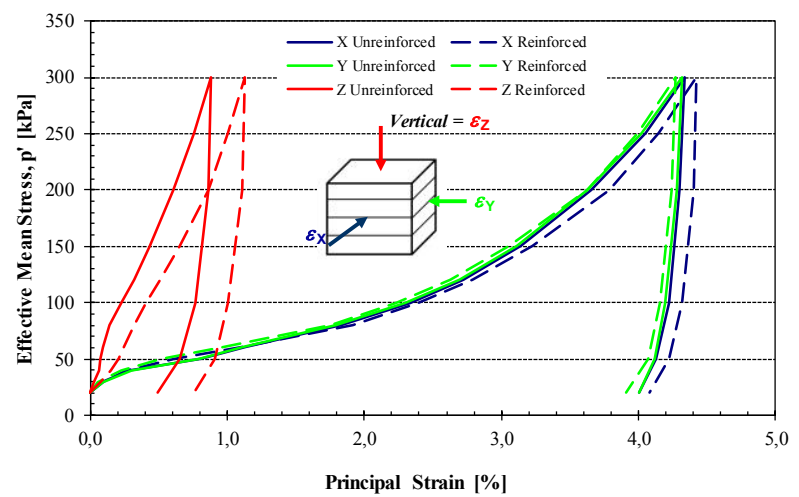

Fig. 1. Effective mean stress vs principal strain curves obtained for IC tests on unreinforced and reinforced specimens.

\subsection{Triaxial shear tests}

The effects of cross anisotropy in the stress-strain behaviour of the unreinforced and reinforced soil specimens can be evaluated by comparing the results of the tests performed in different sectors of the octahedral plane, with the same values of $b$ (same stress path). Figures 2 to 4 show the deviatory stress $(q)$ versus shear $\operatorname{strain}\left(\varepsilon_{q}\right)$ curves for $\mathrm{b}=0.0(\mathrm{TC}), \mathrm{b}=0.5(\mathrm{SS})$ and $\mathrm{b}=1.0$ (TE) respectively, for the unreinforced and reinforced soil specimens being:

$$
\begin{gathered}
q=\sqrt{\frac{\left(\sigma_{1}-\sigma_{2}\right)^{2}+\left(\sigma_{2}-\sigma_{3}\right)^{2}+\left(\sigma_{3}-\sigma_{1}\right)^{2}}{2}} \\
\varepsilon_{q}=\frac{\sqrt{2}}{3} \sqrt{\left(\varepsilon_{1}-\varepsilon_{2}\right)^{2}+\left(\varepsilon_{2}-\varepsilon_{3}\right)^{2}+\left(\varepsilon_{3}-\varepsilon_{1}\right)^{2}}
\end{gathered}
$$

Figure 2 shows the curves of the tests performed on reinforced and unreinforced specimens for $b=0.0$ on the three sectors of octahedral plane $\left(\theta=0^{\circ}\right.$ and $\left.120^{\circ}\right)$. At low strains levels the differences are not significant. However, as deformations increase the higher values in the deviatory stresses for the reinforced specimen becomes evident.

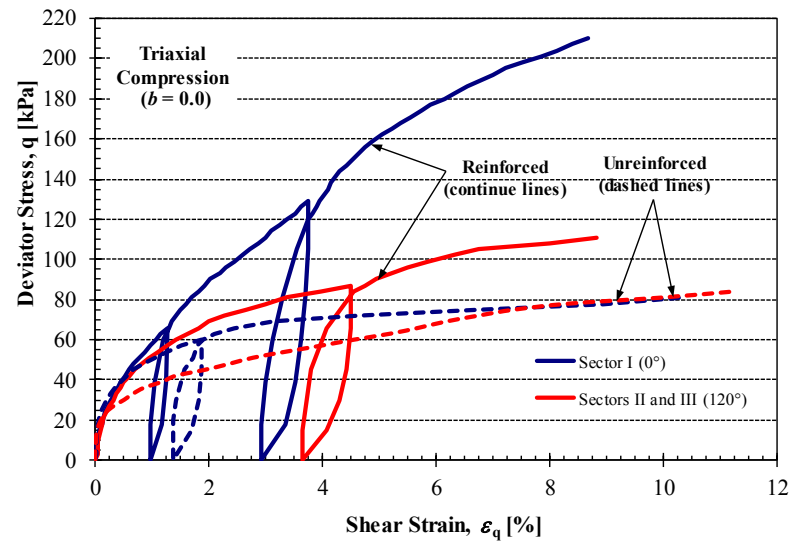

Fig. 2. Stress-strain curves obtained for the tests with values of $\mathrm{b}=0.0(\mathrm{CT})$ in the three sectors of the octahedral plane for the unreinforced and reinforced soil specimens.

Figure 3 shows the results of tests performed for $b=0.5$ (SS) on the three sectors of octahedral plane $\left(\theta=30^{\circ} ; 90^{\circ}\right.$ and $\left.150^{\circ}\right)$. Here, no significant differences were observed between the curves of tests corresponding to unreinforced samples in the three sectors, while the specimen of reinforced soil is stiffer. No influence of reinforcement is observed in sector III. This behavior clearly highlights the effect of the direction of the major and intermediate stresses in the mechanical response of the reinforced soil specimens.

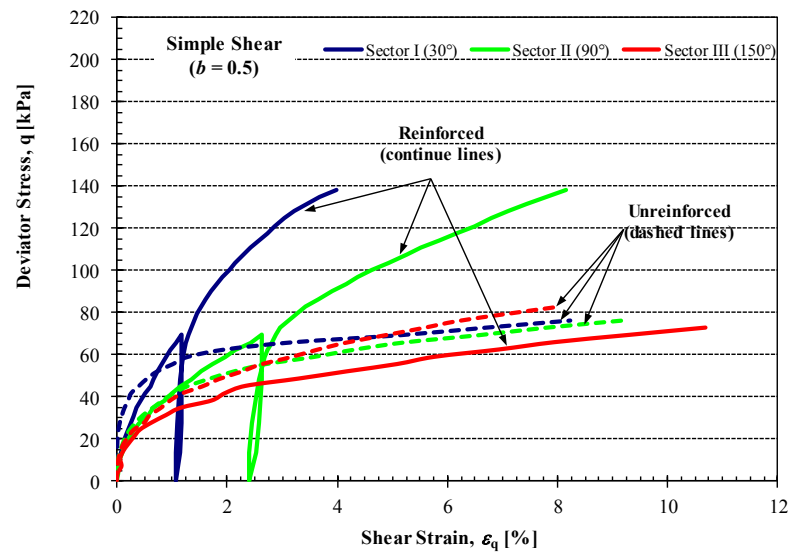

Fig. 3. Stress-strain curves obtained for the tests with values of $\mathrm{b}=0.5$ (SS) in the three sectors of the octahedral plane for the unreinforced and reinforced soil specimens.

Figure 4 shows the results of tests performed for $b=1.0$ (TE) on the three sectors of octahedral plane $\left(\theta=60^{\circ}\right.$ and $180^{\circ}$ ). In this case, the response obtained for the reinforced specimens tested in sectors I and II develop higher strength but lower stiffness with respect to 
specimens tested in sector III. Results in sector III is similar for both reinforced and unreinforced specimens.

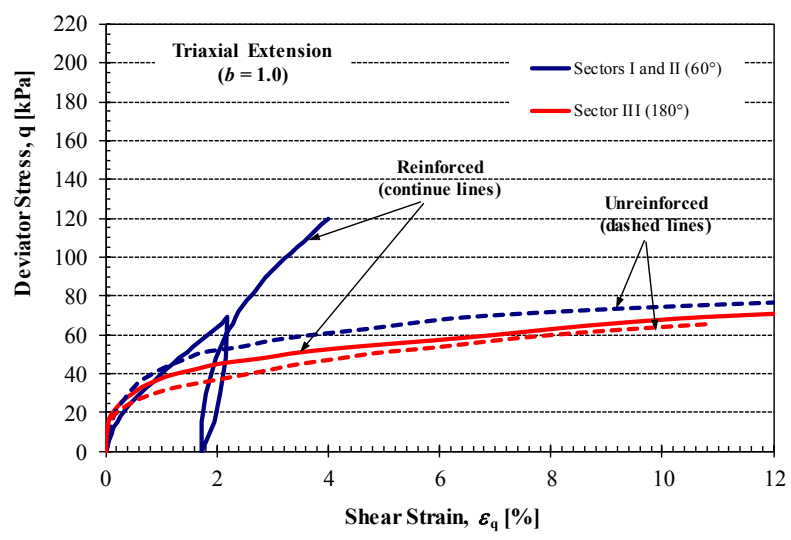

Fig. 4. Stress-strain curves obtained for the tests with values of $\mathrm{b}=1.0$ (TE) in the three Sectors of the octahedral plane for the unreinforced and reinforced soil specimens.

\section{Analysis of the results}

\subsection{Stiffness}

To compare the stiffness of unreinforced and reinforced soil under triaxial shear stress paths, the secant modulus $\mathrm{E}_{50}$ was calculated for the unreinforced soil for each stress path applied in the octahedral plane. Then, the deformation moduli of the reinforced soil were calculated at the same deformation level for each stress path in order to establish a consistent comparison among them. Figure 5 shows the variation of secant modulus calculated $\left(\mathrm{E}_{50}\right.$ for unreinforced soil) with respect to $b$ in each sector of the octahedral plane for the tests performed on unreinforced and reinforced soil specimens.

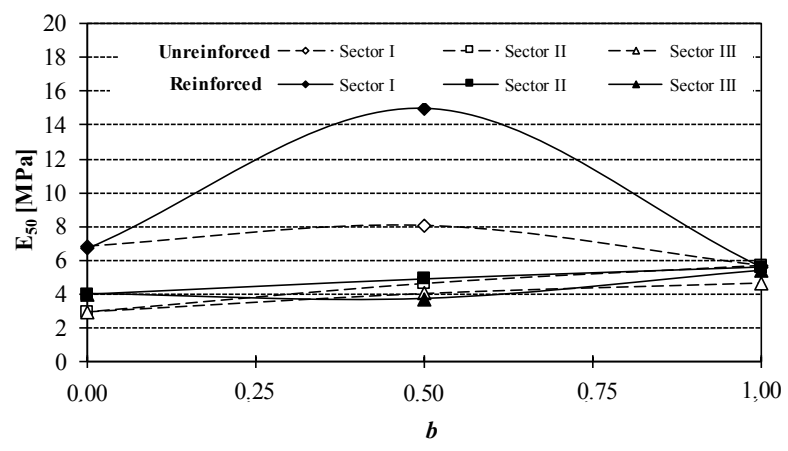

Fig. 5. Variation of the deformation modulus with parameter $b$ for the different specimens tested in the three sectors of octahedral plane.

Figure 5 shows that the secant modulus values are higher in sector I and lower in sector III. On the other hand, in Sector I it is observed that the maximum secant module value corresponds to the value of $b=0.5$, while the module calculated for $b=0.0$ is larger than the module obtained for $b=1.0$, for both unreinforced and reinforced specimens. In the sector $\mathrm{I}$, it can be observed that for $\mathrm{b}=$
0.0 and $b=1.0$ there are practically no differences between the values of secant module measured for the unreinforced and reinforced specimens, while for $b=0.5$ difference of approximately $200 \%$ is observed for reinforced soil specimen with respect to the unreinforced one. In the case of sectors II and III, the lowest values of secant modules were obtained for $\mathrm{b}=0.0$ while the highest values were obtained for $b=1.0$. In these two sectors, no significant differences were observed in the stiffness measured for both unreinforced and reinforced soil specimens.

\subsection{Yielding and strength}

The results of isotropic compression tests show that both the unreinforced and reinforced soil have cross-anisotropy in the vertical axis $(z)$ which is the same as the material axis of the specimens, being the main axis of anisotropy.

Since yielding is observed here as a gradual phenomenon, caution was taken to identify the initial point of yielding. Here, these points on each stress path were determined from the stress-strain curves using the strain energy approach [25-27]. These authors found that the relationship between the length of stress path and the strain energy absorbed by the specimen due deformation should be bilinear for elastoplastic material and the two lines should represent the preyield and postyield behavior. The intersection of both lines is the yielding point. Figure 6 shows the projections of the yielding point in half left of the octahedral plane at $\sigma_{\text {oct }}^{\prime}=80 \mathrm{kPa}$. The points were mirrored towards the right half, closing the state surfaces in the octahedral plane due cross the anisotropic behavior observed. It can be seen that the yielding conditions for the unreinforced and reinforced soil are almost coincident. This fact indicates that the behavior of the reinforced soil below yielding is controlled mainly by the soil phase with no contribution of the reinforcement.

As seen in Figures 2 to 4, for the reinforced soil, the recorded shear strains exceeded more than $8 \%$ in all stress paths except for the tests executed with $\theta=30^{\circ}$ and $60^{\circ}$ in sector I, which reached a maximum of $4 \%$ of shear strain. The reason for this difference is that, during testing, as the principal stresses were increasing and decreasing in a coordinated and at prescribed rate in order to maintain the stress paths on a fixed octahedral plane. Thus, the pressure of the cell in the minor principal direction was decreased to a limited value of $2 \mathrm{kPa}$ (effective). Therefore, it was not possible to continue with these two prescribed stress paths and to obtain extensive data at higher strains. In present work, a state envelope on the octahedral plane at $\varepsilon_{\mathrm{q}}=4 \%$ for all the stress paths for the reinforced soil was defined. Also, a state envelope on the octahedral plane at $\varepsilon_{\mathrm{q}}=4 \%$ for the unreinforced soil was defined in order to establish a consistent comparison among them. Figure 6, also shows the projections off state envelopes for both materials studied. Again, the points were mirrored towards the right half, closing the state surfaces in the octahedral plane. When compared the state envelopes of both unreinforced and reinforced soil, it can be seen that they differ considerably in sectors I and II, while in sector III they tend to be similar. Thus, the actual 
orientation of the reinforcement acts more effectively for the stress paths contained in sectors I and II of the octahedral plane or, in other words, when the major and intermediate principal stresses are normal to the plane of the reinforcement. In the sector III the major and intermediate stresses act parallel to the plane of the reinforcement so that normal forces are not enough to allow the contribution to the geosynthetic.

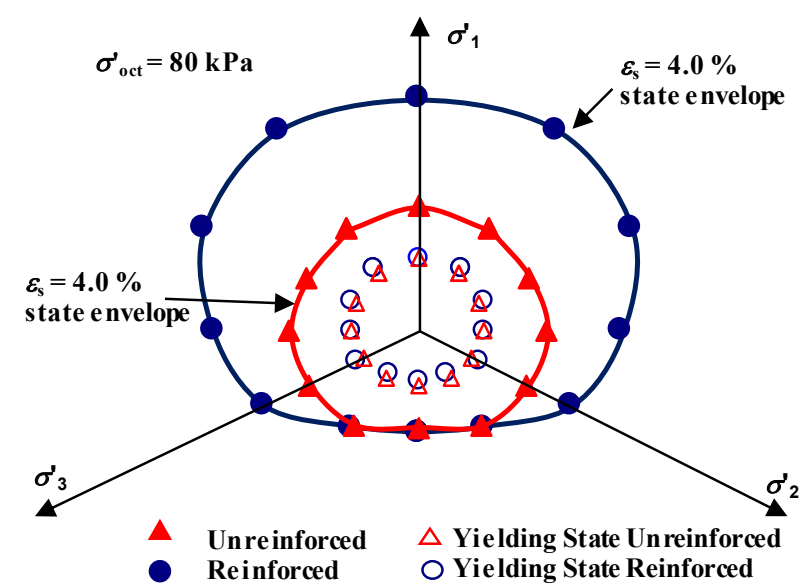

Fig. 6. Yielding points and state envelopes (for $\varepsilon_{s}=4 \%$ ) for reinforced and unreinforced soil specimens tested in this work.

\section{Conclusions}

This work describes the main experimental study on the anisotropic mechanical behaviour induced by a geogrid. The variations in strength and stiffness were measured for both, the unreinforced and reinforced soil specimens. The orientation of the compaction and reinforcement with respect to the principal stresses orientations were considered. The main conclusions obtained in the present work are:

1. The cubical triaxial device used here can be considered as an adequate apparatus to study the anisotropic behaviour of unreinforced and reinforced soils.

2. Under isotropic compression, the unreinforced and reinforced specimens show similar anisotropic behaviour, with higher stiffness observed in the vertical direction. The main difference in stiffness between the unreinforced and reinforced soil was observed in the vertical direction and can be attributed to the higher compressibility of the reinforcement material used with respect to the compacted soil.

3. The stress-strain behaviour of both unreinforced and reinforced soils does not present significant differences at strains levels below yielding. After yielding, the mechanical behaviours depends on the stress paths and the orientation of the principal stresses.

4. Although both unreinforced and reinforced soils have cross anisotropy, it turns out to be more significant in the reinforced soil. The anisotropic mechanical response of reinforced soil is more influenced in Sector I of the octahedral plane, to a lesser extent in Sector II and has practically no influence in Sector III.

5. The influence of the intermediate principal stress is important both in terms of stiffness and strength for the case of reinforced soil.

\section{References}

1. M. X. Zhang, A. A. Javadi, Y. M. Lai, J. Sun, Eur. Geotechnical and Geological Engineering, 24, 903917, (2006).

2. J. T. Germaine, Ph.D. Thesis Massachusetts Institute of Technology, (1982).

3. W. J. Harrison, C. Gerrard, Journal of Soil Mechanics and Foundation Division, ASCE, 98, 1325-1345, (1972).

4. C. Gerrard, Journal of Geotechnical Engineering, ASCE, 108, 1460-1474, (1982).

5. P. de Buhan, R. Mangiavacchi, R. Nova, G. Pellegrini, J. Salencon, Géotechnique, 39 (2), 189201, (1989).

6. R. L. Michalowski, A. Zhao, Journal of Geotechnical Engineering, ASCE, 121, 152-162, (1995).

7. T-C. Chen, R-H. Chen, S-S. Lin, Geotextiles and Geomembranes, 18, 349-366, (2000).

8. P. de Buhan, B. Sudret, Eur. J. Mech. A/Solids, 18, 995-1012, (1999).

9. P. de Buhan, B. Sudret, Eur. J. Mech. A/Solids, 19, 669-687, (2000).

10. B. Sudret, P. de Buhan, Int. J. Analyt. Meth. Geomech., 15, 155-182, (2001).

11. G. Hassen, P. de Buhan, Eur. J. Mech. A/Solids, 24, 987-1001, (2005).

12. E. S. Hosseininia, O. Farzaneh, Geotextiles and Geomembranes, 28, 85-92, (2010).

13. T. S. Ingold, Journal of Geotechnical Engineering, ASCE, 109 (5), 738-744, (1983).

14. T. S. Ingold, K. S. Miller, Journal of Geotechnical Engineering, ASCE, 109 (7), 883-898, (1983).

15. A. K. Ashmawy, P. L. Bourdeau, V. P. Drnevich, M. Dysli, Soils and Foundations, 39(1), 43-52, (1999).

16. S. M. Haeri, R. Noorzad, A. M. Oskoorouchi, Geotextiles and Geomembranes, 18, 385-402, (2000).

17. G. M. Latha, V. S. Murthy, Geotextiles and Geomembranes, 25, 23-32, (2007). 
18. R. Noorzad, S. H. Mirmoradi, Geotextiles and Geomembranes, 28, 23-32, (2010).

19. H. I. Ling, F. Tatsuoka, Journal of Geotechnical Engineering, ASCE, 120, 1166-1184, (1994).

20. A. Cividini, Soils and Foundations, 42 (6), 23-39, (2002).

21. U. Arosio, Proc. 12th International Conference of International Association for Computer Methods and Advances in Geomechanics (IACMAG), (2008), Goa, India.

22. P. A. Covassi, V. A. Rinaldi, 6th International Symposium on Deformation Characteristics of Geomaterials, IS Buenos Aires 2015, Buenos Aires, Argentina.

23. V. Sivakumar, S. J. Wheeler, Géotechnique, 50 (4), 359-368, (2000).

24. Y. J. Cui, P. Delage, Géotechnique, 46 (2), 291-311, (1996).

25. F. Tavenas, J-P. Des Rosiers, S. Leroueil, P. La Rochelle, M. Roy, Géotechnique, 29 (3), 283-303, (1979).

26. J. Graham, M. L. Noonan, K. Lew, Canadian Geotechnical Journal, 20 (3), 503-516, (1983).

27. A. Prashant, D. Penumadu, Journal of Geotech. and Geoenv. Eng., 130 (3), 284-292, (1996). 